\title{
Sobre la esencia del sentimiento. Un diálogo hermenéutico crítico con M. Scheler y M. Henry
}

\section{The essence of feeling. A hermeneutic-critical dialogue with M. Scheler and M. Henry}

\author{
Ángel Enrique GARRIDO-MATURANO \\ (Consejo Nacional de Investigaciones Científicas y Técnicas CONICET)
}

Recibido: 21/06/2013

Aceptado: 14/11/2013

\section{Resumen}

A partir de un diálogo hermenéutico-crítico con el pensamiento primero de M. Scheler y luego de M. Henry el artículo emprende un análisis fenomenológico de los sentimientos en tanto actos intencionales. Primero se elucida la esencia del sentimiento como una estricta correlación entre la auto-afectividad experimentada en el cuerpo viviente (correlato subjetivo) y el carácter patético del mundo (correlato objetivo), y se caracteriza esta correlación en función de una doble reversión de la dirección intencional que se da entre ambos correlatos. Luego se introduce la noción de "interesabilidad" como condición originaria tracendental de posibilidad de todo sentimiento.

Palabras clave: sentimiento, intencionalidad, mundo, cuerpo viviente, interés, pathos, Scheler, Henry.

\begin{abstract}
Drawing on a hermeneutic-critical dialogue first with M. Scheler's position and then with M. Henry's stance, this article attempts a phenomenological analysis of feelings as intentional acts. First, it explores the essence of feeling as a strict correlation between the self-affectivity experienced by the lived body (subjective correlate) and the pathetic character of the world (objective correlate). This relationship is characterized according to a twofold reversion of the intentional direction that holds between both correlates. Second, the notion of "capability of taking
\end{abstract}


interest in" is introduced as an originary transcendental condition of possibility for feelings.

Keywords: Feeling, intentionality, world, living body, interest, pathos, Scheler, Henry.

\section{Introducción}

El estudio de los sentimientos debe vérselas con una serie de complicaciones que se asientan en la naturaleza misma del fenómeno a investigar. En una primera instancia los sentimientos se manifiestan como fenómenos demasiado subjetivos, múltiples y difícilmente distinguibles de otros fenómenos de la vida emocional, como los temples anímicos ${ }^{1}$ o las pasiones ${ }^{2}$. Ello dificulta que puedan ser asidos conceptualmente con precisión. Ante esta indefinición, que resulta del modo positivo mismo de darse el fenómeno, sería posible atenerse a lo estrictamente empírico y limitarse a llevar adelante un registro de las diversas manifestaciones de la vida emocional y de sus modos de expresión. Tal cosa -sumamente útil desde el punto de vista psicológico- no es, en cambio, la tarea propia de un análisis filosófico de los sentimientos. Éste debe retroceder de la descripción de los múltiples modos de darse el fenómeno a los fundamentos que hacen posible que haya sentimientos $\mathrm{y}$ que determinan un sentimiento en tanto que tal. Dicho de otro modo: es menester retroceder, por medio de la reducción eidética, de la multiplicidad de manifestaciones del fenómeno a su esencia, y de la esencia a aquello que esta esencia deja ver o transluce como su fundamento trascendental. Ahora bien, ¿de qué modo hacer acce-

\footnotetext{
1 Aquí utilizaré el mismo criterio clásico que, por ejemplo, Stephan Strasser emplea para distinguir temple de sentimiento: la dirección objetiva del acto intencional. Los sentimientos están referidos intencionalmente a un objeto ("me alegro de algo", "amo a alguien"), mientras que, en el caso de los temples, no me encuentro dirigido a un objeto determinado del mundo. Antes que actos intencionales ellos son estados anímicos integrales, coloraciones o tonalidades, por así decir, que abren mi "ser-enel-mundo" en totalidad y constituyen el suelo disposicional sobre la base del cual se despliegan los sentimientos específicos hacia los objetos de ese mundo. Cf. Strasser, S.: Das Gemüt. Grundgedanken zu einer phänomenologischen Philosophie und Theorie des menschlichen Gefühlslebens, Freiburg, Herder, 1956, p. 111.

2 La pasión, a diferencia del temple, comparte con el sentimiento su carácter intencional, sin embargo, aquí lo que prima no es el modo en que el sujeto capta el objeto, sino una disposición subjetiva o pulsión que provoca que seamos asidos o dominados por un objeto o estado de cosas de modo prevoluntario. S. Strasser observa "que una pasión sólo puede surgir allí donde una disposición -en todo caso latente- del hombre está presente." Y agrega: "La disposición consiste manifiestamente en una receptividad exacerbada y una capacidad de entrega en relación con aquello que se considera -verdadera o pretendidamente- lo valioso por antonomasia. En virtud de ello se vuelve comprensible el fenómeno del ser asido, ser dominado, ser embargado que caracteriza el padecer de la pasión." ( Strasser, S.: op. cit., p. 206).
} 
sible la esencia de algo tan huidizo como es la vida emocional? ¿Cómo es posible determinar la estructura universal de fenómenos por antonomasia particulares? En este punto quisiera proponer la fenomenología trascendental como un método fructífero y viable para ser aplicado a un estudio filosófico del campo de las emociones.

Ciertamente en el debate actual en torno del tema "sentimientos" se reconocen diversas perspectivas que se autodenominan fenomenológicas, además de otros métodos de investigación que aspiran a un "conocimiento objetivo y científico" del mundo emocional ${ }^{3}$. El empleo del método fenomenológico, tal como aquí lo adop-

3 En efecto, luego de que la tradición idealista y las corrientes del empirismo lógico hayan dejado en
un segundo plano el análisis de los sentimientos, en los últimos tiempos puede hablarse como lo hace
W. Henckman de un "giro emocional", no sólo en la psicología, sino también y desde distintas pers-
pectivas en el pensamiento filosófico. Henckmann, W.: "Über Vernunft und Gefühl", en C. Bermes,
W. Henckmann y H. Leonardy (eds.) Vernunft und Gefühl. Schelers Phänomenologie des emotionalen
Lebens, Würzburg, Könighausen \& Neumann, 2003, pp. 9-24; aquí: p. 9. Dentro de este giro y en el
marco de la llamada "nueva fenomenología" se podría citar, ante todo, la obra de Schmitz, H.: System
der Philosophie. Band III/2 Der Gefühlsraum, Bonn, Bouvier, 1998 y su artículo "Gefühle als
Atmosphären und das affektive betroffen sein von ihnen", en H. Fink Eitel y G. Lohmann (eds.), Zur
Philosophie der Gefühle, Frankfurt a. M., Suhrkamp, 1993, pp. 33-56. En este último artículo reafir-
ma Schmitz la tesis expuesta en Der Gefühlsraum y niega que los sentimientos sean estados psicoló-
gicos subjetivos, tal cual lo presuponía la antropología dualista. Para Schmitz los sentimientos consis-
ten en "atmósferas extendidas espacialmente; y el sentir, en el sentido de estar concernido afectiva-
mente por sentimientos, consiste en el adentrarse, experimentable corporalmente, en la cautivación,
que ejercen tales atmósferas." Schmitz, H.: "Gefühle als Atmosphären und das affektive betroffen sein
von ihnen", p. 33. En síntesis, los sentimientos serían modos de experiencia corporal de una determi-
nada configuración del espacio en que se desarrolla la vida del cuerpo. Desde una perspectiva estric-
tamente heideggeriana puede señalarse la obra de Coriando, P.: Affektenlehre und Phänomenologie der Stimmungen. Wege einer Onotologie und Ethik des Emotionalen, Frankfurt a. M., V. Klostermann, 2002. Allí la autora, que concibe su exégesis heideggeriana como hermenéutico-fenomenológica, reduce los sentimientos a su fundamento en los temples y los elucida como modos originarios de encuentro entre Dasein y mundo que des-limitan de modo necesario el uno al otro, aunque no aclara qué sería lo específicamente afectivo de esa deslimitación. Excelente es el estudio, influido por la nueva fenomenología y por Max Scheler, de la española Vendrell Ferran, I.: Die Emotionen. Gefühle in der realistischen Phänomenologie, Berlín, Akademie Verlag, 2008. La autora analiza las emociones como actos originarios, no deducibles de ningún otro fenómeno, en los que se vivencia la correlación de corporalidad viviente e intencionalidad. Los sentimientos serían reacciones a la captación intencional de valores en el sentir. Tales reacciones se experimentan en los modos de sentirse afectado en el cuerpo propio y se manifiestan a través de la expresión. Dentro de la fenomenología habría que señalar también el artículo de Fink Eitel, H.: "Affekte. Versuch einer philosophischen Bestandaufnahme", Zeitschrift für philosophische Forschung, Bd. 40, Heft. 4 (octubre-diciembre) 1986, pp. 520-542. El trabajo, además de ofrecer una visión de conjunto de las tesis centrales de la historia de la filosofía acerca de los afectos, reseña una serie de características esenciales de la afectividad sobre la base de la concepción del sentimiento ya no como un modo original de dirigirse al objeto, sino como una toma de posición activa en relación con un modo pasivo de ser afectado por sensaciones, percepciones, representaciones o pensamientos. El papel esencial y desencadenante del pathos, como el ser tomado o concernido corporalmente por el salirme al encuentro de lo y del otro en el desarrollo de los sentimientos del yo, es el punto central abordado por Waldenfels, B.: "Der leibliche Sitz 
taremos, no parte de una teoría previa que pretenda explicar lo emocional. Por el contrario, la fenomenología, en tanto eidética, toma como punto de partida la descripción del modo de darse del sentimiento, esto es, de la peculiar correlación intencional que acaece en el fenómeno, para luego des-en-cubrir la esencia de ese modo de darse, es decir, aquellos elementos estructurales que se dan en cada una de las donaciones del fenómeno y que lo determinan como tal, esto es, como sentimiento. Finalmente, en un segundo paso, la fenomenología, en tanto trascendental, se pregunta si no hay algún sentimiento originario, es decir, una especie de matriz afectiva desde la cual y como concreciones o realizaciones suyas sean posibles las múltiples tonalidades de la vida emocional. Queda así definido el método, pero también los objetivos de la presente indagación, a saber, describir la esencia del sentimiento y preguntarse si esa misma esencia no trasluce un "sentimiento originario" que sería condición de posibilidad de todos los demás. Ella parte de dos hipótesis, que serán desplegadas a lo largo de este trabajo. En primer lugar, afirma la idea de que los sentimientos son experimentados como una estricta correlación entre el cuerpo viviente y el carácter patético del mundo, caracterizada por una doble reversión de la dirección intencional. Por un lado, la captación que va del "sujeto" que siente hacia el "objeto" sentido revierte en el sujeto produciendo una modificación de la experiencia que él tiene de sí mismo, cuyo lugar es el cuerpo propio (Leib). Pero, por otro y concomitantemente, el padecimiento del "sujeto" del modo en que le sale al encuentro u ocurre el "objeto" (Widerfahrnis) revierte en el objeto mismo revelando el ser-patético -el con-formarse como sufrible o gozable- del mundo. En segundo lugar, la investigación introducirá la noción de "interesabilidad" como condición originaria y ontológicamente constitutiva del ser-hombre desde la cual los sentimientos son posibles.

Ahora bien, estas hipótesis no surgen de la nada, sino que se despliegan desde lo ya pensado, lo ya ganado a los fenómenos mismos en la búsqueda de la elucidación de su esencia. En este sentido hay dos análisis paradigmáticos del sentimiento en la historia de la fenomenología, a saber, los de Max Scheler y Michel Henry, que nos han conducido a las hipótesis expuestas. Por lo tanto el análisis fenomenológico trascendental de los sentimientos habrá de convergir con y desarrollarse desde una hermenéutica crítica de los trazos fundamentales de la concepción del fenómeno de estos dos pensadores. Ellos no han sido elegidos caprichosamente, ni tampo-

der Gefühle", en M. Staudigl y J. Trinks (eds.), Ereignis und Affektivität. Zur Phänomenologie des sich bildenden Sinnes, Wien, Verlag Turia+Kant, 2008, pp. 161-174. En la tradición de la filosofía analítica se encuentra el clásico estudio de las relaciones entre el sentimiento y la racionalidad de De Souza, R.: Die Rationalität des Gefühls, Frankfurt a.M., Suhrkamp, 1997. Un abordaje interdisciplinario de la cuestión lo hallamos en Schubert, V.: (ed.), Der Mensch und seine Gefühle, Eos-Verlag, St. Ottilien, 1985. Finalmente una visión panorámica de las principales teorías psicológicas y filosóficas del sentimiento puede leerse en Meier-Seethaler, C.: Gefühl und Urteilskraft. Ein Pladoyer für die emotionale Vernunft, München, C. H. Beck, 1997. 
co por el mero hecho de que el análisis fenomenológico de la afectividad constituya un tema central del conjunto de su obra, sino porque ellos -como se verá en detalle más adelante- representan un hito en la elucidación de cada uno de los aspectos de aquella específica correlación entre el hombre y el mundo que llamamos sentimiento. En efecto, ningún otro pensador (con excepción tal vez de Kierkegaard) ha no sólo declarado, sino intentado fundamentar en el modo de darse las cosas mismas la prioridad del sentir por sobre toda actividad de la voluntad y del entendimiento. Poner en diálogo crítico a dos pensadores de esa talla no significa reconstruir de modo completo, exhaustivo y erudito sus respectivas posiciones para luego hacer una crítica intrínseca, positiva o negativa, sobre tal o cual aspecto de éstas. El presente no es ni quiere ser un estudio ni de la obra de Scheler ni de la de Henry. Poner en diálogo hermenéutico-crítico a ambos pensadores significa dos cosas. En primer lugar mostrar cómo cada uno de ellos, desde su peculiar perspectiva, pone a la luz un aspecto esencial del darse del fenómeno, a la par que deja en la oscuridad otro. Y, en segundo lugar, cómo la integración de ambas perspectivas es la que permite al intérprete proponer una determinada configuración de la esencia del sentimiento. Ciertamente dicha integración, operada por la explicitación hermenéutica de ambas concepciones, supone, para ser posible, una determinación de sus límites, esto es, de aquel aspecto del darse del fenómeno del que no pueden dar cuenta consideradas unívocamente. Por ello mismo el diálogo en que serán puestas no sólo es hermenéutico, sino hermenéutico crítico.

\section{Scheler y la cuestión del correlato objetivo de los sentimientos como actos intencionales}

\subsection{La teoría de los valores}

En su obra El formalismo en la ética y la ética material de los valores ${ }^{4}$, a la que aquí fundamentalmente nos atendremos, Scheler toma una primera y fundamental decisión en su determinación de la esencia propia de los sentimientos en tanto actos, a saber, distinguir los sentimientos como meros estados emocionales (Gefühlzustände) de los sentimientos como acto de sentir intencionalmente algo (das intentionale Fühlen von etwas). Los estados emocionales pueden ser o bien puramente corporales y localizables físicamente, por ejemplo, el sentimiento de cansancio, de malestar o dolor físico, o bien afectos psicofísicos puntuales como la vergüenza, el amor sensual, el espanto, etc. Lo propio de estos estados emocionales

\footnotetext{
4 Aquí se citará de acuerdo con la siguiente edición: Scheler, M.: Der Formalismus in der Ethik und die Materiale Wertethik. Neuer Versuch der Grundlegung eines ethischen Personalismus, hrsg. von Maria Scheler, Bern, Francke Verlag, ${ }^{41954}$. Sigla: FE.
} 
es su carácter meramente reactivo-subjetivo y el hecho de no ser intencionales, es decir, de no mostrar ninguna referencia originaria a objeto alguno. Se trata, en este caso, de "meros sentimientos", de transformaciones reactivas de carácter físico, psíquico o psicofísico del sujeto sin valor cognoscitivo ni correlato objetivo adjudicable. Los sentimientos como estados emocionales no implican, pues, una "visión" de cierto aspecto del objeto que provoca la reacción emotiva. Así el dolor físico causado por una quemadura no se refiere a objeto alguno, sino a un propio estado del sujeto, ni proporciona tampoco ningún conocimiento del objeto que produjo la quemadura. El vínculo objetivo, por ejemplo causal, entre el cuerpo herido y el objeto que lo ha quemado sólo se da por medio de una representación, pero el dolor en sí no tiene valor cognoscitivo ni nos abre al ser mismo del objeto. Para Scheler estos sentimientos, que incluyen fenómenos tales como arranques de ira o de temor y ciertos estados de ánimo indeterminados de carácter psicofísico son, a diferencia de los sentimientos intencionales, puros estados subjetivos "explicables causalmente" 5 . De los meros estados emocionales se distinguen los sentimientos como actos intencionales. Un primer nivel, todavía rudimentario, de intencionalidad afectiva está dado por "caracteres de temple objetivo-emocionales" como, por ejemplo, "la paz de un río" o "la tristeza de un paisaje"6. Aquí ya hay una referencia a cierta correlación intencional entre el yo y una propiedad accesible afectivamente del objeto, pero es todavía difusa y difícilmente distinguible de los meros estados emocionales. Finalmente llegamos al segundo y más alto nivel de los actos de sentir de carácter intencional: los sentimientos espirituales (geistige Gefühle), que nunca son meros estados subjetivos, sino que tienen como correlato los valores que se dan en el objeto y constituyen el origen o suelo de la afirmación o negación de nuestra relación con el mundo. Escribe Scheler: "En el curso del sentir intencional se nos abre (...) el mundo mismo de los objetos, sólo que precisamente desde su aspecto axiológico."7 El sentir valores guarda, para Scheler, el mismo carácter intencional que la pura representación y, como ella, implica un modo por el cual la conciencia se abre a y conoce el mundo, sólo que ahora lo hace desde el aspecto axiológico inherente a los objetos mundanos. Si los estados emocionales necesitaban de la mediación de la representación para referirse al ser de un objeto, el sentir valores constituye por sí mismo "un acto objetivante que no necesita de ninguna representación" 8 para referirse inmediata y originariamente a su objeto. En los sentimientos se nos abre el mundo de los valores en su realidad efectiva inmediata. Scheler reconoce en el orden afectivo tres distintos tipos de actos de sentir que cumplen distintas funciones cognitivas. De los actos de sentir, que meramente captan la presencia del valor

\footnotetext{
5 FE, p. 271.

${ }^{6}$ Cf. $F E$, p. 271.

7 FE, p. 273.

${ }^{8} F E$, p. 273.
} 
en un objeto, distingue Scheler los actos emocionales que se edifican sobre ellos, y que se dividen en actos de preferir y posponer, y en los actos de amor y de odio. Por los primeros captamos "el rango o grado de los valores, su ser más bajo o más alto"9. Por los segundos se produce una ampliación o estrechamiento del mundo de los valores. Amor y odio ni crean ni destruyen los valores que subsisten en sus portadores y valen objetivamente, ni tampoco uno se cierra al todo del reino de los valores (odio) mientras que el otro se abriría a él (amor), antes bien ellos son actos fundamentales que nos dirigen a ciertos valores más altos y nos apartan de otros más bajos (amor) o a la inversa (odio).

La concepción scheleriana del sentimiento representa un logro ontológico fundamental. En efecto, a diferencia de la tradición que había visto en los sentimientos o bien actos intencionales que, a diferencia de la razón, sólo accedían al mismo aspecto del objeto conocido por la razón, pero de una manera confusa e inadecuada, o bien actos que tenían una dinámica propia independiente de la razón pero que no se referían a objeto alguno, Scheler reconoce en los actos de sentir a la vez su carácter intencional y la genuina especificidad y adecuación de su relación con el peculiar aspecto del objeto captado ${ }^{10}$. El sentir valores es un acto espontáneo e intencional de la conciencia con un correlato objetivo genuino, esto es, es la "conciencia de" un cierto aspecto axiológico del objeto que se da. Este aspecto es diferente de aquel captado por el entendimiento y la conciencia representativa y exige, por tanto, un tipo diferente de acceso a él, a saber, el sentir. A pesar de este logro fundamental la teoría de Scheler presenta (en relación con la elucidación de la esencia del sentimiento y sin pretender hacer una revisión crítica completa de su concepción) dos aspectos cuestionables, que será necesario evaluar no en su negatividad, sino en su positividad, es decir, en aquello que dicha teoría, precisamente por apartar la vista de ello, indirectamente ilumina.

\subsection{El carácter patético del mundo como reversión "objetiva" de la intencionalidad emocional}

El primero de esos aspectos es el del estatus ontológico del valor o, dicho de otro modo, el nexo entre ser y valor. Los valores serían puras esencialidades subsistentes que sólo ocasionalmente resultarían portadas por los bienes. El espíritu humano se elevaría, entonces, más allá de la experiencia del ser del ente que lo porta hasta un puro sentir de los valores, para el cual el ser o no ser de los bienes que los encarnan resulta insignificativo. Como señala S. Strasser, desde el punto de vista

\footnotetext{
${ }^{9}$ FE, p. 274.

10 Paola Ludovica Coriando (cf. op. cit., pp. 23-25 y p. 87) ha explicitado -según mi modo de ver con acierto- este logro ontológico fundamental de la fenomenología scheleriana de los sentimientos.
} 
fenomenológico esta tesis resulta insostenible. Strasser ofrece un ejemplo sumamente significativo. Supongamos que en una ciudad de aguda crisis habitacional a un potencial inquilino se le ofrece una casa cómoda, amplia, de bello diseño, etc. etc., a la que sólo le falta un detalle: el ser, la existencia. Es obvio que todos los presuntos valores de la casa "se precipitan en la nada de la absoluta falta de valor tan pronto como a ella le es privado el valor fundamental, el valor de ser" 11 . La conclusión es clara. Al valor de los bienes "le pertenece en general y necesariamente su ser o su poder ser como fundamento ontológico; en otras palabras: el valor está unido al ser de una manera indisoluble" 12 . Y si el ser es el fundamento de toda propiedad axiológica, entonces no puede haber un acto puramente valorativo, un puro sentir, desligado de la comprensión del modo en que se configura conmigo en un mundo el ser de lo sentido. La separación que realiza Scheler entre el ser cosa de las cosas, que estaría dado en la percepción y el entendimiento, y los valores, que estarían dados a determinadas formas puras de sentir, se revela difícil de sostener. No resulta para nada evidente cuál sería el estatus epistémico de estas formas puras. Ciertamente desde el realismo axiológico se ha postulado la idea de que el sentir valores sería análogo a la percepción de cualidades sensibles como el color. Así como la vista ve los colores, el sentir puro capta los valores. La analogía, sin embargo, resulta cuestionable cuando entran en juego valoraciones complejas como, por ejemplo, el valor estético de una obra de arte, que no es perceptible por un simple "sentir", ni comparable con la visión que percibe el color de una superficie. Por el contrario, tal valoración supone un trasfondo múltiple compuesto, entre otros factores, por el estar instalado en un determinado temple que nos abra a la obra de arte como tal, como así también por la pertenencia a una cultura sensible a ese modo de arte, por una determinada educación estética, por una comprensión de los múltiples significados e interpretaciones que suscita la obra, etc., etc. En una palabra, la belleza de la obra es impensable fuera de la correlación con su peculiar observador y el modo en que éste comprende el mundo en el que él es. Más allá, pues, de lo cuestionable de la analogía, sigue vigente también el problema fundamental que afronta Scheler y cualquiera que afirme que los sentimientos se fundan en un puro sentir valores subsistentes por sí mismo, a saber: ¿cómo concebir el extraño estatus epistemológico de esos valores independientes del sujeto, que estarían presuntamente dados a un igualmente extraño sentir puro y de un modo oscuro vendrían a enriquecer con entidades dudosas el conjunto de lo que es?

Esta primera observación crítica en última instancia nos pone de manifiesto dos cuestiones centrales. En primer lugar que ciertamente los sentimientos -y he aquí nuevamente la gran ganancia ontológica de Scheler en su elucidación de la naturaleza del fenómeno- tienen un correlato intencional específico. Y, en segundo lugar,

11 Strasser, S., op. cit., p. 18.

12 Ibidem. 
que ese correlato intencional se manifiesta y radica en el propio mundo en el que es el sujeto que experimenta el sentimiento. En efecto, si, como lo ejemplifica también el caso de la belleza de la obra artística, el "valor" sólo puede ser vivenciado y tener algún tipo de realidad emocional en la medida en que se da en la correlación que se establece entre un modo de salirme al encuentro lo que es y un modo del sujeto de inter-esarse por lo que es, entonces es innecesario postular ese intermediario ontológicamente oscuro que sería el valor; y se puede simplemente concluir que el correlato intencional del sentimiento es efectivamente un modo de configurarse el mundo que sólo puede ser sentido en la correlación entre ese mundo y el peculiar modo en que el sujeto se abre a o interesa por él. Ahora bien, ¿qué es lo específico de ese modo de abrírseme el mundo que capto en el sentimiento? A esta especificidad del configurarse del mundo, que es captada por el sujeto como sentimiento, podríamos llamarla la pateticidad o carácter patético del mundo, esto es, el hecho de que el mundo en sentido óntico, es decir, el estado de cosas que en cada caso configura el "en que" en el cual se despliega nuestra existencia, no se revela nunca de manera neutra -si así lo hiciese jamás nos interesaríamos por ningún aspecto del mundo y todas las cosas nos darían lo mismo-, sino de un modo tal que nos place o nos displace, nos hace sufrir de un modo u otro o motiva diversas formas de gozo, en una palabra: es susceptible de ser padecido. De hecho, los distintos valores y contravalores en tanto vivenciados emocionalmente por el sujeto se experimentan siempre como distintas formas, más o menos intensas, cada una con su propia peculiaridad (que no viene al caso aquí analizar) de gozo o placer, de displacer o sufrimiento. De allí que ante sentimientos negativos experimentemos concomitantemente una cierta aversión hacia el modo en que nos sale al encuentro el mundo; y ante sentimientos positivos una cierta versión hacia ese darse del mundo. Esta concepción del correlato "objetivo" del sentimiento concebido como carácter patético de una cierta configuración del mundo en el que es un existente concreto presenta ventajas fundamentales que permiten superar problemas intrínsecos a la concepción realista de los valores, al estilo de Scheler, y a la irrealista, que pretende que los valores no son sino la proyección objetiva de voliciones y aspiraciones subjetivas profundas. Respecto de la concepción realista supera su problema mayor, a saber, el del discutible estatus ontológico de los valores. Es un hecho indisputable que somos en un mundo y que nos sentimos a nosotros mismos emocionalmente impactados por el modo en que se configura para nosotros ese mundo. Mientras que los valores subsistentes, separados del estado de cosas en que se dan y concebidos como objetos sui generis de tipo formal o propiedades de objetos son por lo pronto un postulado. Pero, además, supera otro problema colateral de esta concepción, a saber, el hecho de la notoria variabilidad inter e intrapersonal de los presuntos valores. Distintos individuos o un mismo individuo en diferentes momentos tienen sentimientos diversos ante un mismo valor. En realidad, ese problema se disuelve cuan- 
do consideramos como correlato del sentimiento no un valor objetivo, que debería valer siempre lo mismo para todos, sino el con-formarse o no de un estado de cosas con el modo en que se abre al o interesa el por mundo el existente que es en ese tiempo en ese estado de cosas. En efecto, cuando se con-forman o articulan el sentido latente en la configuración del mundo que me sale al encuentro y el sentido deseado en mi propio salir al encuentro de ese mundo, resultan sentimientos de placer o gozo, que serán diferentes en cada caso de acuerdo con el aspecto de ese mundo que me sale al encuentro y la intención o interés con que voy a buscarlo (serían los distintos sentimientos positivos). Cuando, en cambio, se produce una dis-con-formidad acaecen sentimientos de sufrimiento o displacer, nuevamente diferentes de acuerdo con el aspecto de ese mundo que padezco y la intención con la que me dirijo a él. Veamos un ejemplo: busco cierto tipo de fuerza indómita en la naturaleza y me encuentro con el paisaje apacible de una cabaña junto a un lago de aguas mansas. El sentimiento que experimento es el de desagrado o decepción. Pero otra persona, que buscase algo enteramente diferente -digamos un paisaje relajante y no una naturaleza indómita- se encontraría gratificado. Y ello porque lo gozable o sufrible, lo que provoca los múltiples modos de versión o aversión hacia lo que me sale al encuentro, se halla en estricta correlación con el modo en que se dirige al mundo aquel que lo experimenta. Ahora bien, esto debe quedar claro: lo gozable o sufrible, placentero o displacentero está en el mundo, es un aspecto -el carácter patético- con que se me muestra el mundo y no una mera proyección del sujeto, sólo que se revela como tal en el sentimiento que experimenta un sujeto determinado en relación con ese mundo; y la especificidad de ese sentimiento depende a su vez del modo en que ese sujeto se interesa por y se abre al mundo. En síntesis, la comprensión del correlato objetivo del sentimiento como con-formidad o dis-conformidad de un modo de darse el estado de cosas en el que un sujeto es respecto del interés, intención o deseo desde el cual el sujeto se dirige o abre hacia ese estado de cosas, elimina tanto el problema de la relatividad fáctica de valores presuntamente objetivos cuanto el de la existencia dubitable de entidades sui generis que serían los valores. Respecto de la posición irrealista supera la dificultad de por qué no podemos proyectar arbitrariamente sentimientos positivos o negativos en cualquier cosa. ¿Por qué no podemos experimentar el sentimiento del poder indómito de la naturaleza en la tranquila cabañita al lado del remanso? ¿Por qué vemos belleza en una flor y no en un basural? ¿Por qué ciertos tonos y ritmos musicales son tristes y otros alegres? ¿Por qué es bella una catedral gótica y no lo es una estación de servicio? En efecto, si los sentimientos no tuviesen otro correlato objetivo que meras proyecciones subjetivas, entonces no se advierte por qué un sujeto no podría proyectar cualquier valor en cualquier cosa. Si me siento triste una canción exultante me parece triste. Si me siento poseído por la belleza, la estación de servicio de los suburbios me parece hermosa. En realidad esto no es así, porque lo 
valioso -lo triste o bello- no es una proyección del sujeto, sino que es un modo de darse, que trasluce un cierto sentido o configuración que lo articula, del estado de cosas en el que soy. Por ello podemos apreciar como triste un paisaje lluvioso (esto es, una cierta configuración del mundo o estado de cosas) sin que nosotros experimentemos tristeza alguna. Pero, por otro lado, para que ese paisaje no sólo sea apreciado o juzgado como triste ${ }^{13}$, sino que sea el correlato de mi tristeza efectivamente vivida no basta con la configuración triste del mundo, sino que esa configuración debe conformarse o dis-conformarse con una intención mía de ser en ese mundo, por ejemplo, me ofusca el paisaje lluvioso porque quiero salir a entrenar con mi bicicleta. No es, pues, lo patético del mundo una proyección subjetiva ${ }^{14}$, sino una cualidad del mundo; cierto que se trata de una cualidad que sólo se constituye y revela como tal en correlación con el sujeto que se abre desde una determinada intención, interés o deseo a ese mundo que le sale al encuentro; y fuera de la correlación esa configuración no tiene realidad efectiva de índole emocional ninguna. En efecto, si el sujeto no se abriese al mundo desde un determinado interés, entonces todo le sería indiferente y nada tendría valor alguno. Pero, concomitantemente, si el mundo no se le presentara al sujeto de un modo tal que ya siempre resultase placen-

13 El juicio valorativo no debe ser confundido con una emoción, y de lo que aquí hablamos es de la esencia del sentimiento, y no de la del juicio. Puedo estar sumido en la mayor angustia y juzgar alegres o graciosas las monadas de un niño. El juicio no es necesariamente la expresión de un sentimiento. Puede perfectamente ser la representación -neutral desde el punto de vista emocional- de un estado de cosas como motivo de un sentimiento posible.

14 Ingrid Vendrell Ferran, adhiriendo al realismo scheleriano, declara que una ventaja de la postulación de los valores como correlato objetivo de la intencionalidad de los sentimientos radica precisamente en el hecho de poder explicar por qué, por ejemplo, un determinado color o paisaje es asociado con un cierto sentimiento. "Quien dice que nosotros percibimos algo como triste, porque asociamos ciertos aspectos visibles con la tristeza, por ejemplo el gris del cielo, él solo desplaza la pregunta, pues sigue sin responderse por qué nosotros asociamos un determinado color dominante o una cierta disposición de las cosas con un temple o sentimiento específico." (Vendrell Ferran, I., op. cit., p. 198). La autora tiene razón al consignar que el asociacionismo irrealista, que sostiene que los valores no son sino proyecciones, no acierta a responder por qué se hace tales proyecciones en ciertos casos y no es posible en otros. La respuesta no puede ser otra que ésta: porque la tristeza no la provoca una asociación o proyección arbitraria, sino un modo de mostrárseme el mundo mismo, en este caso, como cielo lluvioso. Sin embargo, ese mismo cielo gris es motivo de alegría para el agricultor que espera por la lluvia. ¿Pero no debería ser el cielo gris portador del valor objetivo tristeza? En realidad el sentimiento lo provoca una cierta configuración del mundo, pero esta configuración será un sentimiento de alegría o tristeza de acuerdo con el modo y las intenciones con que se abra a ese mundo el sujeto que experimenta el sentimiento. Tomemos el caso del amor: el enamorado ve perfecciones en su amada que son inaccesibles a otro. ¿Se debe ello acaso a que "idealiza" a su amada? No necesariamente. Esas perfecciones o bondades las manifiesta su amada con él por el modo específico en que los dos se relacionan. Él no proyecta bondades inexistentes, siente bondades que se dan en la amada, pero que lo hacen en la correlación amorosa. Por otro lado, dichas bondades no existen fuera de esa correlación amorosa. La amada no es igual con él que con los demás, por eso -y no porque es un ciego axiológico- quien no está con la señorita del caso en correlación sentimental no puede percibir tales bondades. 
tero o displacentero, sufrible o gozable, entonces no habría ningún sentimiento ni sería, por tanto, posible ninguna proyección de ese sentimiento en ningún objeto del mundo. Se produce, pues, en el caso del sentimiento una peculiar reversión -que llamaremos objetiva- de la intencionalidad emocional o intencionalidad propia del sentimiento: el modo (con-formidad o dis-con-formidad) en que le ocurre el mundo (y el ser con otros esencial a ese mundo) a un existente, abierto a él ya siempre desde una determinada intención o interés, revierte sobre el mundo revelando y haciendo efectivo el carácter patético, es decir, padecible en las distintas formas del placer y del displacer, de ese mismo mundo. El lado activo -el modo en que me abro al mundo desde un determinado interés- y el pasivo -el modo en que el mundo me sale al encuentro- deben ser pensados conjuntamente ${ }^{15}$.

La segunda observación crítica de la que es pasible la concepción scheleriana del sentimiento radica en el hecho esencial de que el fenómeno no se reduce a un modo diferente de percibir el mundo y de captar aspectos de ese mundo, en el caso de Scheler los valores, que no serían accesibles a la racionalidad; no se reduce, en otro términos, a tener una función emocional des-cubridora a través de la cual se da el ser mismo. Todo ello bien puede ser cierto y de hecho aquí se ha sostenido que sólo en el sentimiento se descubre el carácter patético del mundo. Pero el factum fundamental del que ningún modo puede apartar la vista la visión fenomenológica es que en el sentimiento no sólo siento al mundo de un determinado modo, sino que, sintiéndolo, también me siento a mi mismo de un cierto modo. Esto es lo que hace de un sentimiento lo que él es y constituye la parte de verdad de la tradición que consideraba los sentimientos cuestiones subjetivas. En efecto, lo son, porque el sentimiento no es concebible sino como auto-experiencia, como un modo de padecerse el sujeto a sí mismo. Un juicio valorativo, que no tiene por qué ser la expresión de ninguna modificación en el modo en que me siento o experimento a mí mismo, no constituye ningún sentimiento. Los sentimientos son, para usar la expresión

\footnotetext{
15 Holmer Steinfath afirma precisamente que "la tarea de un análisis de la potencial naturaleza constitutiva de valores de los sentimientos consiste precisamente en pensar conjuntamente su rasgo proyectivo con su carácter de ocurrencia padecida (Widerfahrnischarakter)." Steinfath, H., "Gefühle und Werte", Zeitschrift für philosophische Forschung, Bd. 55, Heft 2 (abril-junio), 2001, pp. 196-220; aquí: p. 212. Si aceptamos que el carácter de ocurrencia padecida es propio del modo en que nos sale al encuentro un estado de cosas, y si asimilamos la proyección (que para el autor nunca es arbitraria) al modo en que me abro desde una determinada intención o interés a ese mundo, entonces podría decirse que la tesis aquí defendida coincide en lo esencial con la visión de Steinfath, y particularmente lo hace en la necesidad de pensar juntos ambos aspectos del sentimiento, el activo y el pasivo, que no tienen realidad efectiva independiente: nada sería de valor ni nada sería correlato de un sentimiento, si no nos abriéramos al mundo desde un determinado interés o deseo, es decir, si todo nos fuera indiferente. Pero, por otro lado, porque el mundo nos hiere o nos hace gozar, nada nos es indiferente. Lo que nos hiere o nos hace gozar está en el mundo mismo y el sentimiento revela ese carácter patético del mundo.
} 
agustiniana, "perturbationis animi."16 $\mathrm{Si}$ el propio ánimo, esto es, la propia experiencia de sí no se ve perturbada por un determinado acto intencional, ese acto intencional, sea de la naturaleza que fuera, no es propio de sentimiento alguno. Lo que Heinrich Fink Eitel declara de los afectos en general es esencial a los sentimientos, a saber: "Los afectos no son sólo tomas de posición emocional-cognitivo-prácticas fundadas en estados o procesos físicos respecto de objetos o estados de cosas. Ellos contienen también una señalada relación al sujeto y es esta relación lo que los distingue como tales."17 En el sentirme concernido emocionalmente por un estado de cosas se expresa no sólo una cierta cualidad o modo de ser de ese estado de cosas o mundo, sino también y esencialmente cómo me va a mí en mi ser en relación con él. En la proposición "me enamoré de ella" el reflexivo "me" mienta aquello que hace del amor un sentimiento. El contenido, la materia del afecto -aquello que siento cuando experimento un sentimiento- me confronta no sólo con un estado de cosas a través del cual él ha sido provocado, sino también con mí mismo, con un modo originario de experiencia de sí. Es esta modalización de la experiencia de sí mismo lo que distingue a los sentimientos de las sensaciones pasivo-receptivas de los objetos o de las intenciones activo-objetivas de los instintos, percepciones y representaciones. El sentimiento, concomitantemente con un modo específico de relacionarse con el mundo, es un modo no reflexivo, sino inmediato de relación con la propia vivencia de sí mismo. Precisamente porque en el sentimiento me hallo referido a mí mismo "ellos expresan que su correlato intencional me beneficia o perjudica, es bueno o malo para mí."18 Para poder conciliar esta referencia a sí, que es lo propiamente e-mocional del sentimiento, desde posiciones axiológicas realistas se ha procurado distinguir entre el sentir un valor y los sentimientos que ese sentir ocasiona. El sentir, puro acto intencional de la conciencia como "conciencia de", captaría los valores, nos abriría al mundo axiológico, mientras que los sentimientos no serían intencionales por ver los valores, "sino porque ellos se dirigen esencialmente a un valor [ya captado en el sentir] y responden a él de un determinado modo"19. Habría, pues, que distinguir estrictamente los actos de sentir (fühlen) de los sentimientos o emociones (Gefühle), "que no captan valores, sino que son respuestas reactivas a un sentir de valores." 20 . El problema de esta concepción radica en que presupone de modo implícito un carácter reflexivo y mediatizado de los sentimientos. Todo ocurre como si de modo no emocional, sino cognitivo se captara el valor, luego se tomase una posición respecto a lo captado, y de la reacción a esa toma de posición resultase el sentimiento Pero los sentimientos, como señalaba

\footnotetext{
16 De civitate dei IX, 4.

17 Fink Eitel, H., op. cit., p. 530.

18 Fink Eitel, H., op. cit., p. 531.

19 Vendrell Ferran, I., op. cit, p. 209.

20 Ibidem.
} 
Fink Eitel, no se reducen a una toma de posición -más o menos reactiva- respecto de lo dado objetivamente. Antes bien, ellos son la experiencia originaria e inmediata del cómo me va a mí mismo en mi relación con el mundo o estado de cosas que me sale al encuentro. El dato fenomenológico es que la muerte de un ser querido me pone triste, y no que capto o siento que la muerte de un ser querido es desde el punto de vista axiológico algo triste, y luego, aunque se trate de una posterioridad lógica, experimento la emoción de la tristeza ante lo captado -el valor tristeza- en el sentir. La experiencia de la muerte del ser amado y mi tristeza son co-originarias. Entre el darse del correlato del sentimiento y la experiencia de sí que ese sentimiento provoca no hay intermediario ninguno. El sentimiento se da como un modo de sentir el mundo y no como un modo de sentir el sentir del mundo.

Ahora bien, si lo que constituye al sentimiento es su carácter emocional y esa emotividad se la vive como una cierta experiencia de sí, ¿cómo habrá que concebir al sujeto que se experimenta a sí mismo en el fenómeno originario del sentimiento? Michel Henry ha dado indicaciones decisivas para responder a esta pregunta.

\section{Henry y la cuestión del correlato subjetivo de los sentimientos como actos intencionales}

\subsection{Vida, cuerpo, carne}

Hasta donde mi conocimiento alcanza ha sido Michel Henry quien, dentro de la fenomenología, con más intensidad y profundidad comprendió el vínculo esencial entre el sujeto concebido como vida y el sentimiento como afectividad. En la que tal vez pueda ser considerada su obra principal, La esencia de la manifestación, realiza el filósofo una afirmación fundamental:

Lo que constituye la esencia del sentimiento, la esencia de la afectividad como tal, es sentirse a sí mismo, de tal manera que el sentimiento no es alguna cosa que se siente, tal o cual sentimiento, tan pronto esto como aquello, sino precisamente el hecho de sentirse a sí mismo considerado en sí mismo en la efectividad de su efectuación fenomenológica, es decir, en su realidad. Como tal, como este 'sentirse a sí mismo' fenomenológicamente efectivo (...) la afectividad es la esencia originaria de la revelación. ${ }^{21}$

Del texto de Henry se desprenden tres observaciones esenciales. Primero: que lo que hace que algo sea un sentimiento no es intencionar un objeto, sino sentirse a sí mismo en la experiencia de ese objeto. Segundo: que esa auto-experiencia no es

${ }^{21}$ Henry, M.: L'essence de la manifestation (Tome II), París, PUF, 1963, p. 578. Sigla: EM. 
ninguna explicación o construcción teórica, no necesita fundamentarse con ningún "argumento" ni "teoría", porque se fundamenta a sí misma en cuanto ya siempre padecemos la "efectividad de su efectuación fenomenológica", es decir, en cuanto ya siempre es absolutamente real e indubitable que nos revelamos a nosotros mismos en el hecho de que sentimos nuestra propia vida. Y, finalmente, tercero: que todo aquello que se nos revela en un mundo u horizonte de sentido, toda trascendencia, sólo puede revelarse como vivencia que, en tanto tal, es un modo de sentirse afectado por sí mismo en la inmanencia de sí. En efecto, no tengo una experiencia de algo, sino que me siento a mí mismo vivenciando algo. Ahora bien, si el darse en el horizonte de un mundo es la esencia de todo lo que se manifiesta en la trascendencia, en cuanto ese mundo es aquello sobre lo base de lo cual algo puede manifestarse como el algo que es; y si toda manifestación en el horizonte del mundo se da en y gracias a una vivencia de sí, entonces el sentimiento, concebido como auto-afectividad, es la verdadera esencia de la revelación: aquello que posibilita la manifestación de cualquier trascendencia. En efecto, el sentimiento constituye la condición originaria de posibilidad de la manifestación de cualquier estado de cosas o valor, porque "el sentir como sentir de un contenido sensible y como su recepción en principio sólo es posible sobre el trasfondo del sentirse a sí mismo, (...), en principio sólo es posible como afectividad" 22 .

La esencia del sentimiento es, entonces, para Henry auto-afección. Pero la autoafección es idéntica a la noción fenomenológica de vida. En la vida como autoafección se da la estricta identidad entre lo afectante -la vida que es tal en tanto sentimiento de sí que ya siempre experimenta el sí mismo viviente- y lo afectado -el sí mismo viviente que es tal en tanto siente su propia vida como su sí mismo. La vida es, por tanto, la esencia del sentimiento, porque lo que siente el sí mismo en cada sentimiento es un cómo de la manifestación de su propia vida a sí mismo. Pero la esencia de la vida no es algo distinto de esta manifestación, sino que su esencia se agota en el experimentarse a sí misma, esto es, en su auto-manifestación o "efectuación fenomenológica". La vida es tanto la esencia de la manifestación (porque cualquier trascendencia mundana se muestra en el trasfondo de la vida) cuanto la manifestación de la esencia (pues la esencia de la vida consiste en manifestarse a sí). A esta vida concebida como auto-afectividad o manifestación de sí a sí, a esta vida puramente fenomenológica que constituye la esencia de todo sentimiento, le pertenece como su modalidad todo sentimiento particular. "Él le pertenece en tanto que este sentimiento es cada vez y necesariamente el sentimiento de sí, no en razón de su carácter particular, sino en razón de su carácter afectivo." 23 Los sentimientos no serían sino "las modalidades concretas según las cuales se

\footnotetext{
22 EM, p. 598.
}

23 EM, p. 582. 
cumple cada vez el acto de sentir considerado en sí mismo y en la realidad de su esencia, como afectividad." 24

Concebido esencialmente como auto-afección, todo sentimiento, para Henry, se cumplen "en la inmanencia absoluta de la vida en su pasividad original a la vista de sí." 25 De ninguna manera el sentimiento se funda en la captación intencional de un correlato, no importa de la naturaleza que fuese. Considerando captar el carácter más importante de la afectividad en la intencionalidad "la filosofía moderna no ha hecho más que desconocer su esencia" 26 y convertirla en un mero efecto psicológico fundado en la captación de un objeto trascendente. Pero -insiste Henry- lo verdadero es justamente lo contrario: la afectividad es el fundamento originario de de todos los fenómenos, pues estos no se dan sino en la experiencia de sí y como modos de la experiencia de sí. No hay afectividad porque captamos algo de un modo u otro, sino que podemos captar algo, porque somos esencialmente auto-afectividad. La trascendencia se funda en la inmanencia de la auto-afectividad, que se modaliza en los diferentes sentimientos particulares concebidos como distintas formas del sentirse a sí mismo gozoso o sufriente de sí, y no a la inversa ${ }^{27}$.

El sentimiento se cumple, pues, en la inmanencia del sí mismo que padece (siente) su propia vida. ¿Pero cómo concretamente se siente a sí mismo el sí mismo? La respuesta que da Henry a esta pregunta en Filosofía y fenomenología del cuerpo, una obra posterior, pero fundada en las tesis de La esencia de la manifestación, es clara: el sí mismo se siente a sí mismo como "cuerpo subjetivo". El sí mismo coincide en su ser con el cuerpo, pero no con el cuerpo trascendente u objetivo que se manifiesta de manera cósica a los sentidos y que es el objeto de toda representación cognitiva del cuerpo, sino con el cuerpo subjetivo entendido como el pathos de la propia corporeidad, como la experiencia interna y trascendental (porque sobre su base se constituye cualquier otra experiencia de carácter objetivo) de ser un cuerpo que se experimenta a sí mismo viviendo y que padece todos sus movimientos como modalidades de su vida. Es el cuerpo subjetivo el que se siente a sí mismo y que lo hace en cuanto experimenta su propio movimiento no como algo dado de modo trascendente en el horizonte del mundo, sino "en la experiencia interna trascendental que coincide con el ser mismo de este movimiento." 28 El cuerpo y sus movimientos no son, pues, el instrumento a través del cual realizo mis intenciones en el mundo, sino que el movimiento de nuestro cuerpo es nuestra vida misma que se

\footnotetext{
24 EM, p. 601.

25 EM, p. 608.

26 Ibídem.

27 En tal sentido escribe Henry: "La afectividad es comprensiva porque el comprender [y la intencionalidad AG] es afectivo en la medida en que él es." EM, p. 608.

28 Henry, M.: Filosofía y fenomenología del cuerpo, trad. J. Gallo Reyzábal, Salamanca, Sígueme, 2007. Sigla: FFC.
} 
experimenta a sí misma en sí misma en tanto se ejecuta como cuerpo. Todo movimiento, es decir, toda modificación del estado del propio cuerpo y la vivencia interna y trascendental de sí es una y la misma cosa. El cuerpo es, entonces, originariamente el cuerpo subjetivo, "cuyo ser se revela a sí mismo en una esfera de inmanencia absoluta, y de un modo tal que es uno con esa revelación misma" 29 ; la cual se cumple por excelencia en el sentir-se en el propio movimiento. En contraposición con el cuerpo subjetivo el objetivo es un "cuerpo fundado", es decir, es una representación constituida sobre el fundamento de nuestro cuerpo subjetivo. En síntesis, el sí mismo se siente y se revela a sí mismo ya siempre como cuerpo viviente subjetivo. La vida del cuerpo subjetivo se vivencia en una inmanencia radical, precisamente en el sentimiento de sí que tiene todo cuerpo. Ello se testimonia por excelencia en la experiencia interna del movimiento, en la que el cuerpo se revela a sí mismo de modo inmediato, sin que tal revelación se manifieste ante sí en el horizonte del ser trascendente. Este cuerpo que se siente a sí mismo es, pues, el verdadero sujeto de la auto-afectividad. Y como la auto-afectividad, según vimos, es la esencia de todo sentimiento, los sentimientos no son propiamente una cuestión de la "persona espiritual" o del "yo vital", como creía Scheler, sino del cuerpo subjetivo viviente o, como lo designará Henry en sus últimas obras influidas por un cristianismo gnóstico, de la carne.

En efecto, en su trilogía de obras cristianas y particularmente en La encarnación Henry emplea la palabra cuerpo para los objetos materiales inertes del Universo que no se sienten a sí mismos, reservando el término carne para nuestro cuerpo que sí lo hace ${ }^{30}$. Pero ahora Henry no centra esta auto-afectividad propia del cuerpo viviente básicamente en el movimiento, sino en la "impresividad" de las cosas padecidas por el cuerpo. De la carne afirma el filósofo que "no es otra cosa que aquello que, al experimentarse, sufrirse, padecerse y soportarse a sí mismo y, de este modo, gozar de sí según impresiones siempre renacientes, es susceptible, por esta razón, de sentir el cuerpo exterior a sí, de tocar así como de ser tocado por él."31 Concebido como carne, el cuerpo se manifiesta como aquello en lo que se engendra o-mejor aún- como el engendrarse de la vida misma; y toma su sustancia de la sustancia misma de la vida. A esta sustancia de la carne y de la vida la califica Henry de "sustancia fenomenológica pura" 32 , en tanto y en cuanto el ser de esta sustancia no es otra cosa que el manifestarse a sí misma, el volverse fenómeno de la vida en las impresiones de sí siempre renacientes que es el cuerpo como carne. El sujeto que se experimenta a sí mismo en el fenómeno originario del sentimiento es, pues,

\footnotetext{
29 FFC, p. 256.

30 Henry, M.: Encarnación. Una filosofía de la carne, trad. J. Teira, G. Fernández y R. Ranz, Salamanca, Sígueme, 2001, p. 10 Sigla: $E$.

31 Ibidem.

32 E., p. 159.
} 
según esta última formulación henryana de la cuestión, la carne, pues los sentimientos no son otra cosa que los modos en que nos im-presiona y a-fecta la vida misma en su engendrarse como tal en la carne.

\subsection{La experiencia de sí como reversión subjetiva de la intencionalidad emocional}

Así como Scheler representa un hito en la fenomenología del sentimiento por haber observado que ellos son actos intencionales con un correlato específico al que pueden acceder de modo genuino, asimismo Henry representa otro hito en la fenomenología del sentimiento. Él ha mostrado con una claridad fenomenológica insuperable cuatro aspectos cruciales. Primero: que el sentimiento en tanto tal es autoreferencial. Segundo: que esa auto-referencialidad debe concebirse como auto-afectividad. Tercero: que la auto-afectividad es idéntica al cómo se sufre o goza la vida misma. Y cuarto: que el sujeto del sentimiento es el cuerpo subjetivo o carne. Sin embargo, el análisis henryano puede ser considerado como unilateral en cuanto afirma que los sentimientos se cumplen en la inmanencia radical del cuerpo subjetivo. A mi modo de ver esta última interpretación del sentimiento resulta cuestionable. Su análisis crítico nos permitirá avanzar en un intento de determinación del "correlato subjetivo" de la intencionalidad emocional y de la peculiar reversión que en él se cumple, así como el análisis del pensamiento de Scheler nos permitió avanzar en la determinación del correlato objetivo y de la reversión que le es propia.

Ante todo es cuestionable la idea de la absoluta inmanencia de la auto-afección, pues ella presupone que sería posible sentirse a sí mismo sin sentir concomitantemente y con igual originalidad nada exterior, es decir, que sería posible una experiencia interna del propio cuerpo que no estuviera referida a ninguna exterioridad mundana. Por lo tanto los sentimientos no estarían referidos esencialmente al modo en que me sale al encuentro el mundo, sino a la propia interioridad. En cierto sentido este tesis extrema, a la que el pensamiento de Henry por muchos momentos se acerca al referir y fundar toda experiencia del mundo en la experiencia de sí, corre el riesgo de retrotraer a la fenomenología del sentimiento a una posición anterior a la de Scheler, en cuanto convertiría el fenómeno en una cuestión "puramente subjetiva", a pesar de que explícitamente se comprenda el sujeto no sobre la base de la objetividad cósica, sino de la "vida". Es cierto que lo que hace un sentimiento tal es la auto-afección, pero la auto-afección no se da desde sí misma: sino que me encuentro auto-afectado ya siempre por algo del mundo. Apliquemos el método de variación eidética y tratemos de imaginar un sentimiento en el que el sujeto se sienta a sí mismo, pero que no lo haga en función de la experiencia de algo, y observaremos que no es posible ofrecer ni un solo ejemplo. Herny en Filosofía y fenome- 
nología del cuerpo habla de la sensación de movimiento como absolutamente interna y trascendental, pero ninguno de los argumentos que ofrece puede explicar cómo es posible el movimiento sin el espacio, sin un trayecto recorrido. Y el espacio es, por excelencia, la dimensión de la trascendencia. ¿Qué es un movimiento que no se mueve "a través de"? El hecho fenomenológico no es la sensación interna trascendental del movimiento; el hecho fenomenológico es la sensación de sí mismo moviéndose en un mundo. Lo primero es una pura abstracción. Incluso los cambios cualitativos como el pasar de triste a contento, son cambios en el modo de experimentar algo, esto es, el mundo. No sólo el sentimiento, que es siempre sentimiento de sí sintiendo algo, sino también los temples refieren necesariamente al mundo o a su ausencia, que es un modo indirecto de referir a él. El tan mentado fenómeno fundamental de la angustia, en la que todo pierde sentido, diferenciación y significación, en la que el sujeto, por decir así, pierde todo vínculo concreto con el mundo y no siente otra cosa que su propia vida, que el propio fluir de su conciencia, está directamente referida a la exterioridad del mundo, sólo que en el modo negativo de su ausencia. Henry tiene absolutamente razón al insistir que todo sentimiento se da no como el contenido de conciencia de una persona espiritual o de una "psiquis", entendida del modo en que se la entienda. Los sentimientos se dan en el modo en que experimentamos nuestro propio cuerpo o, mejor aún, en el que el cuerpo viviente se experimenta a sí mismo. Pero el cuerpo no se experimenta a sí mismo, sino a través de la experiencia del mundo 33 . De allí que cada sentimiento se exprese con gestos corporales de versión o aversión -movimientos en el espacio- que tienden a o se apartan de aquello que me sale al encuentro desde el mundo y que los ocasiona. La alegría conlleva una compulsión a expandirse hacia el exterior y gestos de extro-versión. La pena un movimiento de intro-versión y una cierta parálisis, que no es sino un movimiento "negativo" del cuerpo en el espacio que lo rodea. La paz de ribetes místico-religiosos se advierte por una imperceptible pero constante sonrisa y va acompañada de movimientos uniformes, ligeros y armónicos. Los ejemplos muestran lo que la variación eidética puede fundamentar, a saber: que no es posible pensar un sentimiento que no implique un cierto tras-torno en el cómo de la experiencia del propio cuerpo; pero también que el cuerpo viviente, que constituye la esencia del sí mismo, sólo se experimenta a sí mismo experimentando lo otro que sí: un elemento trascendente que se da en el horizonte de un mundo o estado de cosas. Si llevamos la cuestión a un punto extremo, concluiremos que es imposible

\footnotetext{
33 Bernhard Waldenfels ha observado ya con razón que el cuerpo en tanto lugar de los sentimientos no está ni en las puras cosas sentidas ni en la inmanencia del alma que siente, sino que presupone la correlación entre ambas. El sentimiento - escribe Waldenfels- "presupone un ser que no está ni por completo fuera de sí, como las cosas extensas de la naturaleza, ni enteramente consigo mismo, como el puro espíritu." Y agrega: "Su lugar es el cuerpo, que se siente en la medida en que siente algo o alguien otro.” Waldenfels, B., op. cit., p. 167.
} 
pensar un cuerpo que no se sienta a sí mismo respirando, pero el aire que respira no es inmanente, sino que está afuera en el mundo. La vida no vive de sí misma ni se vive a sí misma, sino que vive de aquello que vivencia y que la alimenta, incluso (y sobre todo) en un sentido literal. Sentimientos básicos como la satisfacción que provoca una buena comida se experimenta en la inmanencia de la sensación que el cuerpo tiene de sí, pero obviamente sería imposible sin la comida. Por ello Levinas, que, como Henry, reconoce como intencionalidad original la de la vida afectiva y no la de la conciencia representativa, menciona como modo originario de la intencionalidad "el vivir de algo" 34 , por lo pronto del aire que respiramos o de la "buena sopa" que ingerimos. ¿Cómo podría sentir-se a sí mismo de un cierto modo un cuerpo, sino se siente respirando? ¿Y no es este gozo del respirar la forma más fundamental y primera de todo sentimiento, la forma más inmediata y no representativa de sentirse a sí mismo vivo? Podría suscribir en un todo la siguiente afirmación de Levinas: "La vida que es vida de algo, es felicidad. La vida es afectividad y sentimiento." 35 Pero lo es en tanto es vida "de algo". Es tan imposible imaginarse una relación con la exterioridad que me sale al encuentro que no se viva como una experiencia de sí mismo, como una experiencia de sí que no sea, a la vez, un modo de experiencia del mundo, aunque más no fuera una experiencia del nulificarse del mundo, como ocurre en el caso de la angustia. Es tan cierto que la auto-afectividad es fundamento trascendental de toda relación con la exterioridad, porque toda vivencia del mundo es un modo de sentirme a mí mismo, como que el modo de salirme al encuentro del mundo es fundamento de la auto-afectividad, porque si el mundo no me saliera al encuentro de ningún modo, si él no fuera gozable o sufrible, mi cuerpo no se sentiría a sí mismo de modo alguno. Ambos fenómenos -la facultad de sentirse a sí mismo del cuerpo viviente o subjetivo y el salirme al encuentro del mundo como sufrible o gozoso, como susceptible de ser padecidoson fenómenos co-originarios que sólo se constituyen en lo que son en la correlación que ya siempre está dada entre ellos. Entre el aparecer patético del mundo y el sentimiento de sí hay una relación de fundación mutua ${ }^{36}$. Indirectamente Henry presupone esta correlación, pues en La Encarnación define, como vimos, el cuerpo viviente como carne y la carne como "impresividad". La impresividad es impensable como tal sin ser impresionada por algo. Es cierto que nada puede impresionar a aquello que no es impresionable. Pero igualmente no es concebible una impresivi-

\footnotetext{
34 Cf. Levinas, E.: Totalidad e infinito. Ensayo sobre la exterioridad., trad. D. Guillot. Salamanca, Sígueme, pp. 129-133.

35 Levinas. E., op. cit., p. 134. (Cursivas mías).

36 Esta constitución correlativa de la realidad efectiva del mundo en la experiencia de sí y de la experiencia de sí a través de la relación con el mundo en ciertos momentos parece reconocerla el propio Henry cuando, por ejemplo, afirma que el cuerpo "se experimenta a sí mismo al mismo tiempo que siente lo que le rodea”. E, p. 10.
} 
dad o impresionalidad que no estuviera referida a lo que lo impresiona ${ }^{37}$. En conclusión, si en la sensación que el sí mismo tiene de sí mismo no estuviera dado a la vez el modo en que este sí mismo siente el ocurrirle del mundo, la sensación de sí sería un puro vacío, una nada. ¿Cuál es, entonces, la consecuencia que el diálogo crítico con el pensamiento de Scheler y de Henry trae para la determinación de la esencia del sentimiento y su fundamento trascendental?

\section{Conclusión: la esencia del sentimiento y su condición trascendental de posibilidad}

El diálogo crítico con la posición paradigmática scheleriana puso de manifiesto que en su esencia los sentimientos no son estados meramente psicológicos no referidos a nada, ni modos oscuros de comprender lo que comprendería mejor la razón, sino actos intencionales que se refieren de un modo genuino y adecuado a su "objeto". Éste se reveló no como un valor subsistente por sí mismo o como una mera proyección axiológica subjetiva, sino que el correlato objetivo del sentimiento se lo halló en lo que llamamos el carácter patético del mundo, esto es, en el salirnos al encuentro del mundo (y el "ser con" los otros que se da en el mundo) a través de un estado de cosas configurado de modo tal que se con-forma o dis-conforma con el interés a partir del cual nos dirigimos a ese mundo, y que, por tanto, resulta sufrible o gozable, placentero o displacentero en múltiples modos. Se producía así una peculiar reversión de la intencionalidad propia de los sentimientos, a saber, el modo en que el salirle al encuentro del mundo a-fecta al y es padecido por el sujeto, revierte sobre el mundo mismo mostrando que él se da no sólo como objeto de una representación cognitiva neutra, sino como patético, como sufrible o gozable. En este primer aspecto objetivo de la intencionalidad del sentimiento se funda la hoy día clásica afirmación de que el fenómeno nos abre a nuevos modos de signi-ficar, de hacernos signo del mundo, y que amplía, de este modo, el horizonte no óntico, sino ontológico. El sentimiento no nos abre a nuevos entes que sólo existirían para él, sino a nuevas posibilidades de signi-ficar propias del mundo mismo, a nuevos aspectos o modos del darse del mundo, cuya específica afectividad radica en los múltiples modos de gozo y de sufrimiento que provoca en el sujeto; más precisamente en el cuerpo subjetivo que se siente a sí sintiendo el mundo.

Es precisamente en este punto dónde el diálogo crítico con el pensamiento de Scheler se conjuga con el de Henry. En efecto, el estudio de la concepción henryana ha puesto de manifiesto que el sentimiento para ser tal no es sólo un modo diferente de captar un aspecto igualmente diferente del objeto, sino que, concomitante-

37 "Interpelable, impresionable, afectable lo somos sólo en la medida en que nunca somos del todo y enteramente inmanentes a nosotros mismos." Waldenfels, B., op. cit., p. 167. 
mente con ello, el sentimiento se da siempre como un modo sufriente o gozoso de vivenciar la propia vida: es auto-referencial. Esta auto-referencialidad se da como auto-afectividad, es decir, como el sentirse a sí mismo de un cierto modo, que es lo que hace del sentimiento lo que él es. El sentirse a sí mismo se cumple por excelencia en el cuerpo subjetivo o viviente, que goza o sufre, y se expresa en la gestualidad. Pero este sentirse a sí no es una experiencia absolutamente inmanente, que pudiera tenerse con independencia del mundo, sino que es una relación que mantengo conmigo mismo a través del modo en que padezco la manera en que se me presenta o ausenta el mundo. El correlato subjetivo de la intencionalidad propia del sentimiento debe ser pensado, entonces, en estricto inter-juego con el correlato objetivo, pues ambos se fundan y constituyen en la correlación que se da entre ellos y resultan co-originairos. El correlato subjetivo está caracterizado también por una nueva y peculiar reversión de la intencionalidad: el movimiento que va del sujeto, que ya siempre se siente a sí mismo de un cierto modo en el mundo y que en función de ese modo se dirige al mundo en el que es con un cierto interés o deseo, revierte, en el caso del sentimiento, sobre el sujeto, produciendo una modificación en el cómo de la vivencia de su propia vida, de su propio sentirse a sí. En este segundo aspecto subjetivo de la intencionalidad del sentimiento se funda la hoy día clásica afirmación de que el sentimiento es estrictamente individual e individualizante y en su materialidad propia incognoscible. En efecto, es un hecho que no podemos sentir el sentimiento del otro en su especificidad estrictamente individual. Aunque podamos abrirnos al modo en que el otro comprende el mundo a partir de sus sentimientos y aunque podamos representarnos cómo siente el otro su objeto, no podemos sentir el sentimiento del otro, porque éste acaece como una modificación de su vivencia de sí y no sólo como revelación de una nueva significación del mundo.

Ahora bien, el correlato objetivo y el subjetivo del acto intencional sólo son distinguibles en el análisis, pero se dan concomitantemente como aspectos de una misma estructura. En el caso del sentimiento no puede pensarse ninguna dirección del sujeto (el sí mismo encarnado) al objeto (un cierto estado de cosas en que se configura el mundo) que revierta sobre el sujeto modificando el modo en que experimenta en su propio cuerpo el carácter gozable o sufrible de la vida, sin pensar conjuntamente la dirección del objeto al sujeto que revierte sobre ese objeto revelando el carácter patético que le es propio al mundo. Ambos movimientos del acto intencional se constituyen en la correlación y cualquier intento de supeditar uno a otro es una abstracción.

Podríamos, sin embargo, finalizar, preguntándonos si no hay un afecto originario; si no existe una afectividad matriz de la cual todos los otros sentimientos no fueran sino una modificación. No me pregunto por un sentimiento señalado, que por una u otra razón destacaría sobre los demás, como lo hace la angustia para Heidegger o el amor para Scheler, sino por una condición afectiva originaria que 
hiciera posible trascendentalmente todos los sentimientos, sea cual fuera para cada análisis la importancia de cada uno de ellos. Me arriesgo a llamar este fenómeno: el interés (inter-esse). Al hombre, desde que respira por primera vez en este mundo hasta su última exhalación, le interesa de un modo u otro su propio ser y el ser que lo rodea. El llanto del recién nacido muestra que no nos es indiferente ni nuestra piel ni el dolor que en ella sentimos. La mirada angustiosa del moribundo delata que no le da lo mismo ser que no ser. A ambos, al que viene y al que se va, y a todo hombre en todo momento por su propia condición de hombre le va, le interesa su ser y el ser de aquello que es en relación con él. Si el ser no nos interesara, no podría haber ni siquiera conocimiento ni comprensión del ser, pues no nos importaría nada, no seríamos propiamente hombres. El hombre se siente a sí mismo siempre de un determinado modo, siente cómo le va. Y si puede sentir cómo le va es porque le interesa este ir mismo, porque el hombre padece en lo más profundo de su ser el interés por su ser y por el ser de lo que es. El hombre no es comprensión del ser, sino y como condición de posibilidad de cualquier relación con o comprensión del ser, es interés por el ser. Si el ser -el nuestro y el del mundo- nos fuera indiferente, igualmente nos sería indiferente toda comprensión. Sin embargo, el término interés no debe aquí ser malentendido. El interés aquí mentado, la existencia como sostenerse en el inter-esse, nada tiene que ver con un interés consciente y utilitario por algo, como, por ejemplo, el agricultor que se interesa por el clima porque de ello depende su cosecha. Aquí mentamos el interés como una pasibilidad originaria, como una susceptibilidad primi-genia que no presupone ninguna actividad de nuestra parte. Se trata, en una palabra, del hecho, al que en tanto vivientes ya siempre estamos entregados, de no poder no interesarnos de un modo u otro por nuestra propia vida y por todo aquello que nos sale al encuentro y con lo que nos relacionamos (el horizonte del mundo). Todo interés concreto, como el del agricultor, no es sino una respuesta a esta susceptibilidad primigenia del inter-esse. Y este inter-esse es la condición trascendental última de posibilidad del sentimiento. En efecto, si no nos sintiéramos a nosotros mismos ya siempre interesados de alguna manera por nuestro ser, que es siempre estar en relación con aquello que nos sale al encuentro, todo nos sería indiferente; no iríamos hacia ello con ninguna intención o deseo y, por lo tanto, lo que nos enfrentase no se conformaría ni desconformaría con nada, ni, consecuentemente, generaría sentimiento ni respuesta emocional alguna. El hombre que se enamora, se enamora porque le interesa el amor, porque es susceptible a él. De no ser así no conocería sus delicias. El aburrimiento es el temple que, por excelencia, muestra el carácter constitutivo originario de lo que hemos llamado interés. El aburrimiento, como el no poder interesarse por nada, no es la indiferencia, sino que es un modo de sufrimiento. Al hombre no le da lo mismo aburrirse que no, sino que sufre estar aburrido. Y si sufre su aburrimiento, si sufre no poder interesarse concretamente por las cosas, ello testimonia que originariamente en su ser es susceptible a su ser y al del universo. 
Si el hombre existe, si se siente de una manera u otra a sí mismo, a los otros y las cosas, es porque su propio ser y el modo en que se le manifiesten las cosas no le es indiferente. Pero -insisto- no es que no le sea indiferente por decisión suya, sino porque no puede serle indiferente. Vivir es experimentarse susceptible al modo en que en mí el universo se manifiesta. Dicha susceptibilidad o interés originario que también podría expresarse (si se me permite el neologismo) con el término "interesabilidad", radica en el hecho de que me vaya, me importe o me e-mocione ("me mueva a") de un modo u otro el cómo de la donación del ente. La interesabilidad constituye, pues, la condición de posibilidad de toda reacción emocional y, por tanto, de todo sentimiento. ¿De dónde proviene esta interesabilidad? ¿Por qué somos susceptibles al ser, al nuestro y al del mundo, o, mejor dicho, al nuestro en nuestra relación con el mundo?

Michel Henry sostuvo que el sentir nuestra propia vida sintiéndonos a nosotros mismos, que constituye la esencia del sentimiento, era el donarse de la Vida Absoluta o Dios en cada viviente. La forma en que Dios mismo devenía fenomenológico. Jan Patoçka consideraba que, siendo nosotros en tanto seres vivientes un momento creado por la dinámica que el universo mismo es, esa proto-afectividad que he denominado "interesabilidad" constituye aquel punto arquimédico en el que el movimiento ontológico revierte en fenomenológico. Aquel punto en el cual el universo se siente a sí mismo, siente - diría yo-su propio carácter patético en los sentimientos que habitan en mi cuerpo. Un cuerpo que también es suyo, pues soy una manifestación del universo. Ambas posiciones son en cierto punto radicalmente diferentes. Una, la de Henry, implica la diferencia esencial entre el ser del mundo que no se siente a sí mismo y el de la Vida que se siente a sí misma en su absoluta inmanencia. La otra, la de Patoçka, implica la convergencia en la existencia de la vida del hombre y la del universo. Ambas respuestas a la pregunta por el origen de los sentimientos tienen, sin embargo, un punto en común: abandonan el terreno estrictamente fenomenológico para rozar el campo de la especulación religiosa o cosmológica. No es éste el lugar para reconstruir, ni evaluar, ni pronunciarse acerca de ninguna de las dos posiciones. Si aquí han sido traídas a colación es tan sólo para ilustrar el carácter fundamental de la cuestión del sentimiento. Tan fundamental que la respuesta a la simple pregunta "¿por qué tenemos sentimientos?" lleva al pensamiento más allá de los límites de la fenomenología misma, pero es esa misma fenomenología del sentimiento la que legitima la necesidad de la pregunta.

\author{
Ángel Enrique Garrido-Maturano \\ Consejo Nacional de Investigaciones Científicas \\ y Técnicas (CONICET) \\ hieloypuna@hotmail.com
}

